\title{
Optimization of Extraction key Process for Erinacine from Hericium erinaceus
}

\author{
Jinzhe He \\ College of Ocean, Zhejiang University of Technology, \\ Hangzhou, 310032, People's Republic of \\ China.hejzgd@163.com
}

\begin{abstract}
In order to improve the yield of erinacine from $\mathbf{H}$. erinaceus, with pretreatment of enzymatic and acid hydrolysis, then combined with the method of industrial alcohol reflux extraction, significantly the extraction yield of erinacine was improved from $2.4 \%$ to $3.2 \%$. In order to optimize extraction process parameters for erinacine from $\mathrm{H}$. erinaceus, the content of erinacine in $\mathrm{H}$. erinaceus as the raw material was measured to evaluate the effects of extraction liquid/material ratio, extraction ethanol/water ratio, extraction temperature and extraction time by single factor experiments and response surface methodology (RMS). Results indicated that the optimal extraction conditions for erinacine from $\mathrm{H}$. erinaceus were extraction liquid/material ratio of $32 \mathrm{ml} / \mathrm{g}$, ethanol/water ratio of $65 \%$, extraction temperature of $62{ }^{\circ} \mathrm{C}$ and extraction time of 30min.Under the condition of the correction, the actual measured extraction yield of erinacine was $3.28 \%$.
\end{abstract}

Keywords- erinacine; enzymatic and acid hydrolysis; yield; response surface.

\section{Introduction}

H. erinaceus in taxonomy attached fungus world, Basidiomycota, basidiomycetes, Hericium genus. Previous studies reported that the fungal mycelia of $\mathrm{H}$. erinaceus contains various bioactive constituents such as polysaccharides(1), proteins, lectin(2), hericenones(3), erinacines(4, 5), sterol, fatty acid and esters(6). $\mathrm{H}$. erinaceus has beneficial effects, including anti-cancer activity(7), antibacterial activity (8, 9), anti-inflammatory

\author{
Qiang Shen \\ College of Ocean, Zhejiang University of Technology, \\ Hangzhou, 310032, People's Republic of \\ China.shenqiangsmile@163.com
}

activity(10, 11), antioxidant properties(12) and stimulating the synthesis of nerve growth factor(13).

In the previous papers, erinacine which was extracted from $\mathrm{H}$. erinaceus exhibited potent stimulating activity to NGF-synthesus $(14,15)$, antibacterial activity and antioxidant properties. Stimulators of NGF-synthesis had been expected to be used as drugs for degenerative neuronal disorders such as Alzheimer's disease and for peripheral nerve regeneration $(4,5)$. Since the yield of erinacine was very low, as reported in the literature using solvent reflux extraction, microwave extraction, ultrasonic extraction and supercritical fluid extraction rate was less than $2.4 \%$ and the extraction costs were high, so the further extraction and exploitation of erinacine became the bottleneck(16).

In order to improve the yield of erinacine from $\mathrm{H}$. erinaceus, with pretreatment of enzymatic and acid hydrolysis, then combined with the method of industrial alcohol reflux extraction, significantly the extraction yield of erinacine improve from $2.4 \%$ to $3.2 \%$. Based on single factor experiments and response surface methodology (RSM), the extraction process parameters were optimized for erinacine extraction provides a good production prospects.

\section{Materials and methods}

\section{A. Materials}

Fungal mycelia of $\mathrm{H}$. erinaceus powder(Beijing $\mathrm{f}$ $\mathrm{u}$ er kang biotechnology research institute), 95\% indust rial alcohol, hydrochloric acid, acetic acid, sulfuric ac 
id, perchloric acid,absolute ethyl alcohol, vanillin, petr oleum ether, ethyl acetate, cellulose enzyme, wild sta ndard scutellarin.

\section{B. Instrument}

UV-7504ultraviolet and visible spectrophotometert her, mostat water bath, AL-104electronic scales, RE-2 000Arotary evaporators.

\section{Experimental method}

\section{1) Technological process}

The fungal mycelia of $\mathrm{H}$. erinaceus powder produced by drying $\rightarrow$ Enzymatic hydrolysis with cellulase $\rightarrow$ Destroy the enzyme activity $\rightarrow$ evaporated to dryness $\rightarrow$ Industrial alcohol solvent reflux extraction $\rightarrow$ Filtration $\rightarrow U$ v-vis $\quad$ spectrophotometer measure of absorbance values $\rightarrow$ The optimal technological conditions were obtained.

2) Test method

a) Constant temperature solvent extraction

The dry fungal mycelia of $\mathrm{H}$. erinaceus powder was accurately weighed $10 \mathrm{~g}$ (accurate to $0.0001 \mathrm{~g}$ ) by AL-104 electronic scales. The fungal mycelia of $\mathrm{H}$. erinaceus powder was circularly extracted with $100 \mathrm{ml}$ of $95 \%$ ethanol solvent in a $500 \mathrm{ml}$ round bottom flask.

\section{b) Pretreatment of enzymatic hydrolysis solvent extraction}

The dry fungal mycelia of $\mathrm{H}$. erinaceus powder was accurately weighed $10 \mathrm{~g}$ (accurate to $0.0001 \mathrm{~g}$ ) by AL-104 electronic scales. The dry fungal mycelia of $\mathrm{H}$. erinaceus powder was put in $250 \mathrm{ml}$ beaker containing $100 \mathrm{ml}$ of water and $0.1 \mathrm{~g}$ of cellulose enzyme. The $\mathrm{pH}$ value was adjusted to 4.5 by hydrochloric acid. After enzymatic hydrolysis $90 \mathrm{~min}$ of $50^{\circ} \mathrm{C}$ and inactivated boil for 10 minutes, the combined extracts were then concentrated on rotary evaporator at $50^{\circ} \mathrm{C}$ to remove water to dryness. The fungal mycelia of $\mathrm{H}$. erinaceus powder was circularly extracted with $100 \mathrm{ml}$ of $95 \%$ ethanol solvent in a $500 \mathrm{ml}$ round bottom flask.

\section{c) Pretreatment of acid hydrolysis solvent extraction}

The dry fungal mycelia of $\mathrm{H}$. erinaceus powder was accurately weighed $10 \mathrm{~g}$ (accurate to $0.0001 \mathrm{~g}$ ) by AL-104 electronic scales. The dry fungal mycelia of $\mathrm{H}$. erinaceus powder was put in $250 \mathrm{ml}$ beaker containing $100 \mathrm{ml}$ of water and $0.1 \mathrm{~g}$ of cellulose enzyme. The $\mathrm{pH}$ value was adjusted to 2 by hydrochloric acid. After acid hydrolysis $24 \mathrm{~h}$, he combined extracts were then concentrated on rotary evaporator at $50^{\circ} \mathrm{C}$ to remove water to dryness. The fungal mycelia of $\mathrm{H}$. erinaceus powder was circularly extracted with $100 \mathrm{ml}$ of $95 \%$ ethanol solvent in a $500 \mathrm{ml}$ round bottom flask.

d) Pretreatment of both enzymatic hydrolysis and acid hydrolysis solvent extraction

The dry fungal mycelia of $\mathrm{H}$. erinaceus powder was accurately weighed $10 \mathrm{~g}$ (accurate to $0.0001 \mathrm{~g}$ ) by AL-104 electronic scales. The dry fungal mycelia of $\mathrm{H}$. erinaceus powder was put in $250 \mathrm{ml}$ beaker containing $100 \mathrm{ml}$ of water and $0.1 \mathrm{~g}$ of cellulose enzyme. After enzymatic hydrolysis $90 \mathrm{~min}$ of $50^{\circ} \mathrm{C}$ and inactivated boil for 10 minutes, the $\mathrm{pH}$ value was adjusted to 2 by hydrochloric acid. After acid hydrolysis 24h, he combined extracts were then concentrated on rotary evaporator at $50^{\circ} \mathrm{C}$ to remove water to dryness. The fungal mycelia of $\mathrm{H}$. erinaceus powder was circularly extracted with $100 \mathrm{ml}$ of $95 \%$ ethanol solvent in a $500 \mathrm{ml}$ round bottom.

\section{Qualitative appraisal of erinacine}

Erinacine existed in alcohol extract was measured by thin layer chromatographic analysis of developing solvent of ethyl acetate and petroleum ether system as the color of terpenoids general indicators respective were ethanol and vanillin sulfuric acid sulfate ethanol.

\section{E. Maximum absorption maxima and calibration plot}

$2 \mathrm{~mL}$ diluted extract in quartz colorimetric utensil was scanned between $200 \sim 400 \mathrm{~nm}$ wavelength, then the operation was repeated for three times. Its maximum absorption peak was discovered at about $210 \mathrm{~nm}$ (UV), so $210 \mathrm{~nm}$ (UV) was selected for detective wavelength.

Wild standard scutellarin which had strong absorption peak around $210 \mathrm{~nm}$ (UV) was accurately weighed $0.02 \mathrm{~g}$ (accurate to $0.0001 \mathrm{~g}$ ). And the wild standard scutellarin was dissolved in $25 \mathrm{~mL}$ absolute ethyl alcohol for $0.8 \mathrm{mg} / \mathrm{mL}$ standardized solution. $0.2 、 0.4 、 0.6$ 、 $0.8 、 1.0 \mathrm{~mL}$ of $0.8 \mathrm{mg} / \mathrm{mL}$ standardized solution was accurately transferred into the $50 \mathrm{~mL}$ volumetric flask respectively and was added up to $50 \mathrm{~mL}$. The different 
concentration standardized solution was shook for uniformity and the OD value was measured in $210 \mathrm{~nm}$ (UV) respectively. Calibration plot was drew with the $\mathrm{OD}$ value $\mathrm{Y}$ as the ordinate and the concentration $\mathrm{X}$ as abscissa.regression equation : $\mathrm{Y}=79.872 \mathrm{X}-0.0369$, $\mathrm{R}^{2}=0.9981$.Extraction yield linear range was $0.82 \%$ $4.07 \%$ and the content of the sample was calculated by the calibration plot.
The yield of erinacine from $\mathrm{H}$. erinaceus was measured by ultraviolet spectroscopy. H. erinaceus extraction rate $/ \%=\mathrm{c} * \mathrm{~V} * \mathrm{n} / \mathrm{m} * 100 \%$

Formula: c was the concentration of erinacine, $\mathrm{mg} / \mathrm{mL}$; $\mathrm{v}$ wastotal volume, $\mathrm{mL}$; $\mathrm{n}$ was the dilution ratio; $\mathrm{m}$ was the quality of $\mathrm{H}$ erinaceum powder, $\mathrm{mg}$.

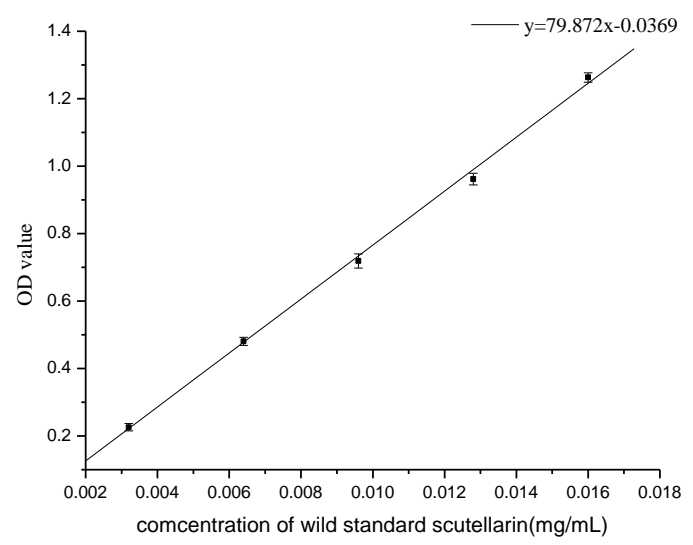

Figure 1. Calibration plot

III. Discussion and Results

A. Discussion

1) Different pretreatment on the effect of erinacine extraction yield
The erinacine extraction yield(Table 1) of four different pretreatment was compared. Then result showed that pretreatment of both enzymatic hydrolysis and acid hydrolysis solvent extraction can make the the yield of erinacine

to improve significantly.

\section{TABLE I.COMPARISION OF THE YEILD WITH DIFFERENT PRETREATMENT}

\begin{tabular}{ccc}
\hline & OD & Extraction yield/\% \\
\hline $\begin{array}{c}\text { Constant temperature solvent extraction } \\
\text { Pretreatment of enzymatic hydrolysis solvent } \\
\text { extraction }\end{array}$ & 0.536 & 1.793 \\
$\begin{array}{c}\text { Pretreatment of acid hydrolysis solvent extraction } \\
\text { Pretreatment of both enzymatic hydrolysis and acid } \\
\text { hydrolys is solvent extraction }\end{array}$ & 0.787 & 2.579 \\
& 0.854 & 2.789 \\
\hline
\end{tabular}




\section{2) Single factor experiment}

a) The influence of extraction liquid/material ratio on erinacine extraction

H.erinaceum powder was accurately weighed 10 $\mathrm{g}$ (accurate to $0.0001 \mathrm{~g}$ ). It was extracted by diferent extraction liquid/material ratio ( 10:1,20:1,30:1,40:1,50:1) and other conditions about reflux extraction were ethanol/water ratio $95 \%$, extraction temperature $60^{\circ} \mathrm{C}$, extraction time $30 \mathrm{~min}$.

Figure 2 show that with the increase of liquid/material ratio the erinacine extraction yield was increased, but when the liquid/material ratio increased more than 30:1 the erinacine extraction yield tended to be stable. Maybe the erinacine had been extracted completely when the liquid/material ratio achieved 30:1. As the factors of the yield of erinacine, dosage of solvent and energy loss were considered comprehensively, the optimization extraction liquid/material ratio of the solvent refluxextraction was about 30:1.

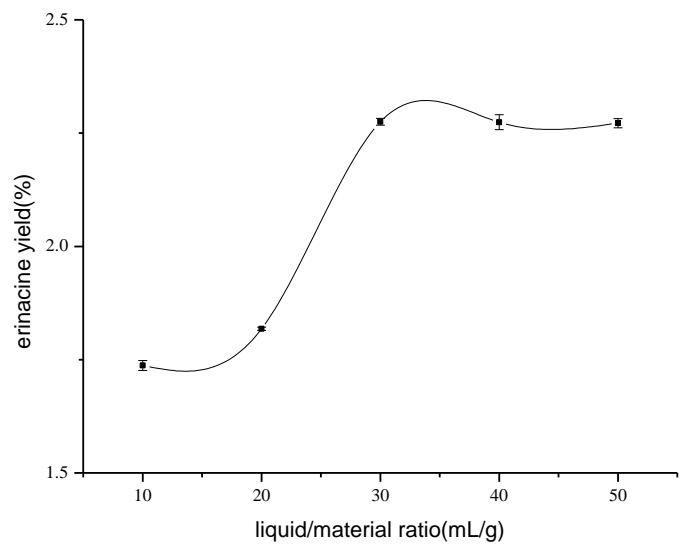

Figure 2. The influence of extraction liquid/material ratio on erinacine extraction

b) The influence of ethanol/water ratio on erinacine extraction

H.erinaceum powder was accurately weighed $10 \mathrm{~g}$. It was extracted by diferent extraction ethanol/water ratio $(55 \%, 65 \%, 75 \%, 85 \%, 95 \%)$ and other conditions about reflux extraction was extraction liquid/material ratio 30:1, extraction temperature $60^{\circ} \mathrm{C}$, extraction time $30 \mathrm{~min}$.

Figure 3 show that with the increase of ethanol/water ratio the erinacine extraction yield was increased, but when the ethanol/water ratio increased more than $65 \%$ the erinacine extraction yield tended to decline. Maybe other substances of freely soluble in organic solvent were extracted which influenced the extraction yield of erinacine. So the optimization extraction ethanol/water ratio of the solvent reflux extraction was about $65 \%$. Figure 3 also show that the influence of ethanol/water ratio change was not very great significant on erinacine extraction. 


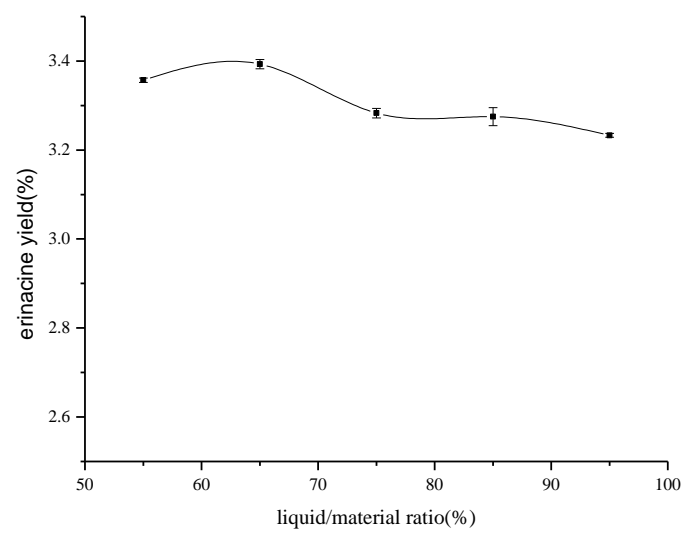

Figure 3. The influence of extraction ethanol/water ratio on erinacine extraction

c) The influence of extraction temperature on erinacine extraction

H.erinaceum powder was accurately weighed 10 $\mathrm{g}$ (accurate to $0.0001 \mathrm{~g})$. It was extracted by diferent extraction temperature $\left(50^{\circ} \mathrm{C}, 60^{\circ} \mathrm{C}, 70^{\circ} \mathrm{C}, 80^{\circ} \mathrm{C}, 90^{\circ} \mathrm{C}\right.$ ) and other conditions about reflux extraction was extraction liquid/material ratio 30:1, extraction ethanol/water ratio $65 \%$, extraction time $30 \mathrm{~min}$.
Figure 4 show that with the increase of extraction temperature the erinacine extraction yield was increased, but when the extraction temperature increased more than $70^{\circ} \mathrm{C}$ the erinacine extraction yield tended to decline. The structure and biological activity of erinacine may be destroyed by the high temperature. So the optimization extraction temperature of the solvent reflux extraction was about $70^{\circ} \mathrm{C}$.

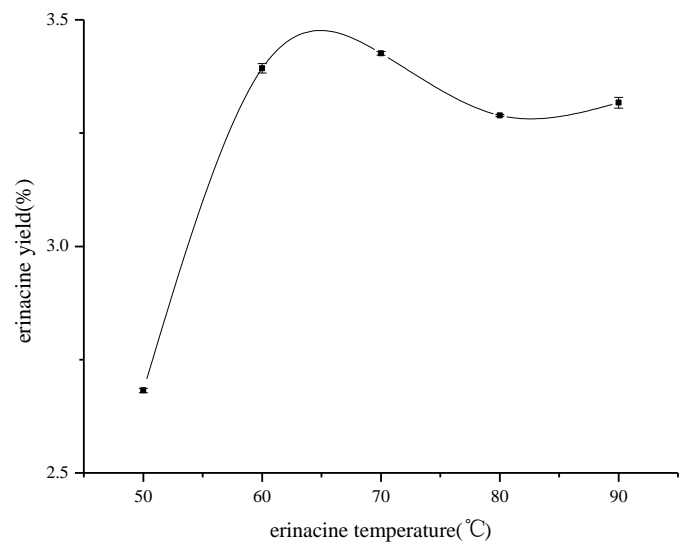

Figure 4. The influence of extraction temperature on erinacine extraction

d) The influence of extraction time on erinacine extraction

H.erinaceum powder was accurately weighed 10 $\mathrm{g}($ accurate to $0.0001 \mathrm{~g})$. It was extracted by diferent extraction time (10min, 20min, 30min, 40min, 50min ) and other conditions about reflux extraction was extraction 
liquid/material ratio 30:1, extraction ethanol/water ratio $65 \%$, extraction temperature $70^{\circ} \mathrm{C}$.

Figure 5 show that with the increase of extraction time the erinacine extraction yield was increased, but when the extraction time increased more than $30 \mathrm{~min}$, the erinacine extraction yield tended to decline. The increase of time influenced the erinacine stability made erinacine extraction yield tended to decline after $30 \mathrm{~min}$. So the optimization extraction time of the solvent reflux extraction was about $65 \%$.

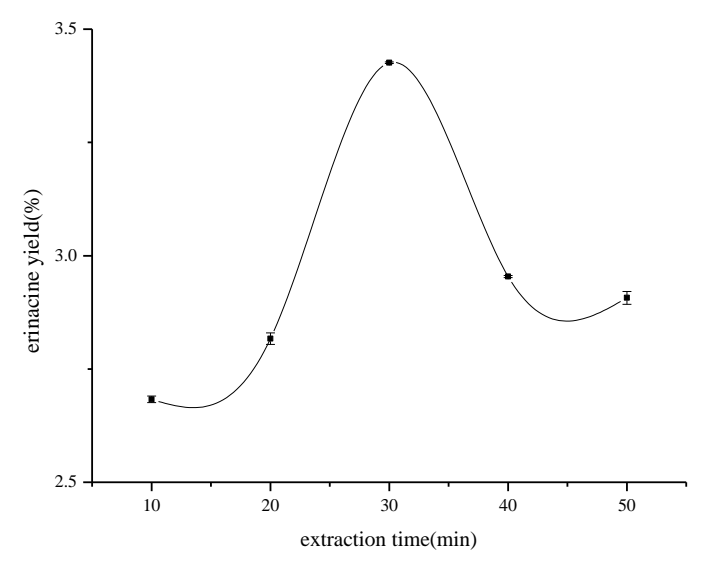

Figure 5. The influence of extraction time on erinacine extraction

\section{3). Response surface methodology}

According to the results of Single factor experiments (Fig. 2 5),three major influence factors (liquid/material ratio, extraction temperature, extraction time) were selected for next experiments because the influence of ethanol/water ratio change was not very great significant on erinacine yeild. On the basis of the single factor experiment results, the ranges of each factor were confirmed, and then a three variables $\left(\mathrm{X}_{1}\right.$, liquid/material ratio; $X_{2}$, extraction temperature; $X_{3}$, extraction time), three levels Box-Behnken design (DesignExpert software, Trial Version 8.0.6 ) was used to evaluate the best condition parameters for the extraction of erinacine. For statistical calculation, the above three values were coded as the following equation:

$X_{1}=\left(X_{1}-30\right) / 10, X_{2}=\left(X_{2}-60\right) / 10, X_{3}=\left(X_{3-30}\right) / 10$.

The experimental runs for Box-Behnken design were shown in Table 2. Each experimental run was per-formed in triplicate and the averages of the yield of erinacine were taken as response.

TABLE II. INDEPRNDENT VARIABLES AND THEIR LEVELS IN BOX-BEHNKEN DESIGN.

\begin{tabular}{ccccc}
\hline & & & \multicolumn{2}{c}{ Level } \\
\cline { 4 - 5 } Independent variables & Symbol & -1 & 0 & 1 \\
\hline Liquid/material ratio / $\mathrm{mL} / \mathrm{g}$ & $\mathrm{X}_{1}$ & 20 & 30 & 40 \\
Extraction temperature $/{ }^{\circ} \mathrm{C}$ & $\mathrm{X}_{2}$ & 50 & 60 & 70 \\
Extraction time / $\mathrm{min}$ & $\mathrm{X}_{3}$ & 20 & 30 & 40 \\
\hline
\end{tabular}


TABLE III. BOX-BEHNKEN EXPERIMENTAL DESIGN AND THE RESULTS FOR EXTRACTION YIELD OF ERINACINE( $\mathrm{n}=3$ ).

\begin{tabular}{|c|c|c|c|c|c|}
\hline \multirow{2}{*}{ Run } & \multicolumn{3}{|c|}{ Coded variable levels } & \multirow{2}{*}{$\begin{array}{c}\text { Sample quality } \\
\qquad / \mathrm{g} \\
\end{array}$} & \multirow{2}{*}{ Yield of erinacine $1 \%$} \\
\hline & $\mathrm{X}_{1}$ & $\mathrm{X}_{2}$ & $\mathrm{X}_{3}$ & & \\
\hline 1 & -1 & -1 & 0 & 10.0003 & 2.828 \\
\hline 2 & 1 & -1 & 0 & 10.0010 & 2.770 \\
\hline 3 & -1 & 1 & 0 & 10.0011 & 2.916 \\
\hline 4 & 1 & 1 & 0 & 10.0012 & 3.162 \\
\hline 5 & -1 & 0 & -1 & 10.0006 & 2.812 \\
\hline 6 & 1 & 0 & -1 & 10.0012 & 2.893 \\
\hline 7 & -1 & 0 & 1 & 10.0021 & 2.836 \\
\hline 8 & 1 & 0 & 1 & 10.0011 & 2.943 \\
\hline 9 & 0 & -1 & -1 & 10.0004 & 2.790 \\
\hline 10 & 0 & 1 & -1 & 10.0013 & 2.837 \\
\hline 11 & 0 & -1 & 1 & 10.0014 & 2.746 \\
\hline 12 & 0 & 1 & 1 & 10.0002 & 2.954 \\
\hline 13 & 0 & 0 & 0 & 10.0005 & 3.355 \\
\hline 14 & 0 & 0 & 0 & 10.0007 & 3.396 \\
\hline 15 & 0 & 0 & 0 & 10.001 & 3.353 \\
\hline 16 & 0 & 0 & 0 & 10.0006 & 3.385 \\
\hline 17 & 0 & 0 & 0 & 10.0007 & 3.388 \\
\hline
\end{tabular}

As shown in Table 3, each experiment in the design was performed and the experimental data were obtained. The data were analyzed by multiple regression analysis using the Design Expert software to get the following polynomial equation:
$\mathrm{Y}=3.38+0.047 * \mathrm{X}_{1}+0.092 * \mathrm{X}_{2}+0.018 * \mathrm{X}_{3}+0.076 * \mathrm{X}_{1} * \mathrm{X}_{2}+6$ $500 \mathrm{E}-003 * \mathrm{X}_{1} * \mathrm{X}_{3}+0.040 * \mathrm{X}_{2} * \mathrm{X}_{3}-0.21 * \mathrm{X}_{1}{ }^{2}-0.25 * \mathrm{X}_{2}{ }^{2}-0.30$ $* \mathrm{X}_{3}{ }^{2}$

TABLEIV. ANALYSIS OF VARIANCE OF THE EXPERIMENTAL RESULTS OF THE BOX-BEHNKEN DESIGN.

\begin{tabular}{|c|c|c|c|c|c|}
\hline Variables & SS & $\mathrm{DF}$ & MS & F-value & $\begin{array}{l}\text { P-value } \\
\text { Prob }>\text { F }\end{array}$ \\
\hline Model & 1.02 & 9 & 0.011 & 100.20 & $<0.0001$ \\
\hline$X_{1}$ & 0.018 & 1 & 0.018 & 15.62 & 0.0055 \\
\hline $\mathrm{X}_{2}$ & 0.068 & 1 & 0.068 & 59.67 & 0.0001 \\
\hline $\mathrm{X}_{3}$ & $2.701 \mathrm{E}-003$ & 1 & 7.503E-003 & 2.39 & 0.1663 \\
\hline $\mathrm{X}_{1}^{2}$ & 0.018 & 1 & 0.18 & 161.87 & $<0.0001$ \\
\hline $\mathrm{X}_{2}^{2}$ & 0.26 & 1 & 0.26 & 228.52 & $<0.0001$ \\
\hline$X_{3}^{2}$ & 0.37 & 1 & 0.37 & 325.61 & $<0.0001$ \\
\hline $\mathrm{X}_{1} \mathrm{X}_{2}$ & 0.023 & 1 & 0.023 & 20.42 & 0.0027 \\
\hline $\mathrm{X}_{1} \mathrm{X}_{3}$ & $1.690 \mathrm{E}-004$ & 1 & $1.690 \mathrm{E}-004$ & 0.15 & 0.7106 \\
\hline
\end{tabular}




\begin{tabular}{cccccc}
\hline $\mathrm{X}_{2} \mathrm{X}_{3}$ & $6.480 \mathrm{E}-003$ & 1 & $6.480 \mathrm{E}-003$ & 5.73 & 0.0480 \\
Residual & $7.921 \mathrm{E}-003$ & 7 & $1.132 \mathrm{E}-003$ & & 0.0706 \\
Lack of fit & $6.328 \mathrm{E}-003$ & 3 & $2.109 \mathrm{E}-003$ & 5.30 & \\
pure error & $1.5932 \mathrm{E}-003$ & 4 & $3.9833 \mathrm{E}-004$ & & \\
Cor Total & 1.03 & 16 & & \\
\hline
\end{tabular}

The F-value and p-value were used to measure the significance of the coefficients of the model and results were shown in Table 4. The analysis of variance (ANOVA) of the quadratic regression model demonstrated that the model was highly significant $(\mathrm{p}<0.0001)$ and the result suggested that the model is adequate for predicting within the range of the variables employed. It also can be seen $t$ hat the variables with the significant effects on the yield of erinacine were the linear terms $\left(\mathrm{X}_{1}, \mathrm{X}_{2}\right)$, the quadratic terms $\left(\mathrm{X}_{1}^{2}, \mathrm{X}_{2}{ }^{2}\right.$ and $\left.\mathrm{X}_{3}{ }^{2}\right)$ and the interaction between $\mathrm{X}_{1}$ and $X_{3}, X_{2}$ and $X_{3}$. the determinant coefficient $\left(R^{2}\right)$ were 0.9923 which indicated that the polynomial model equation had a high quality fit, a good precision and reliability. Response surfaces were plotted by Design Expert software to explain the interactions of the variables and to determine the optimal level of each variable for the maximum response. Three-dimensional response surfaces were shown in Figs. 2 3. Each figure showed the effects of two factors on the the yield of erinacine while the other one was kept at zero level. The 3-D plot in Figs. 6, which set the extraction time at zero level,showed that the yield of erinacine increased with increasing of liquid/material ratio and extraction temperature at the initial stage and then slightly decreased. Figs. 7 showed the3-D plot at varying liquid/material ratio and extraction time. The3-D plot based on independent variables extraction temperature and extraction time were shown in Figs. 8, while the liquid/material ratio was kept at zero level.

The analysis of response surface was performed by Design Expert software to determine the optimal extraction conditions. The optimal extracting conditions were liquid/material ratio $31.52 \mathrm{~mL} / \mathrm{g}$, extraction temperature $62.12{ }^{\circ} \mathrm{C}$, extraction time $30.47 \mathrm{~min}$, respectively. The maximum predicted yield of erinacine was $3.39 \%$.

As the actual operation convenience was considered, the best extraction conditions for erinacine were changed for liquid/material ratio $32 \mathrm{ml} / \mathrm{g}$, extraction temperature $62{ }^{\circ} \mathrm{C}$, the extraction time for $30 \mathrm{~min}$. Under the condition of the correction, the actual measured extraction yield of erinacine was $3.28 \%$.

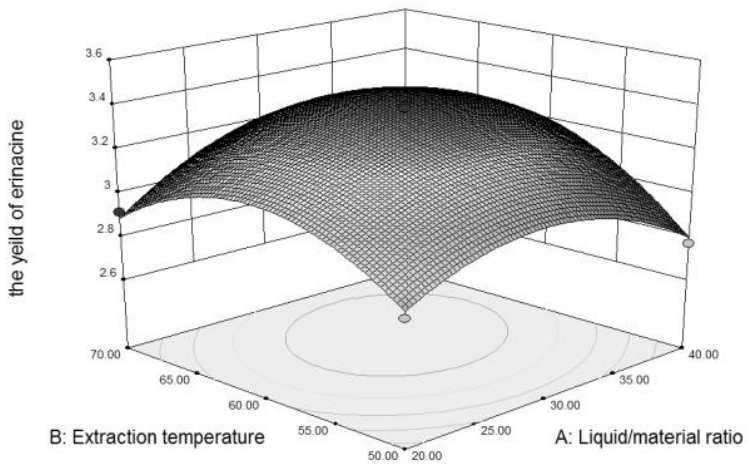

Figure 6. Response surface polts showing the effects of liquid/material ratio and extraction temperature on yield of the erinacine 


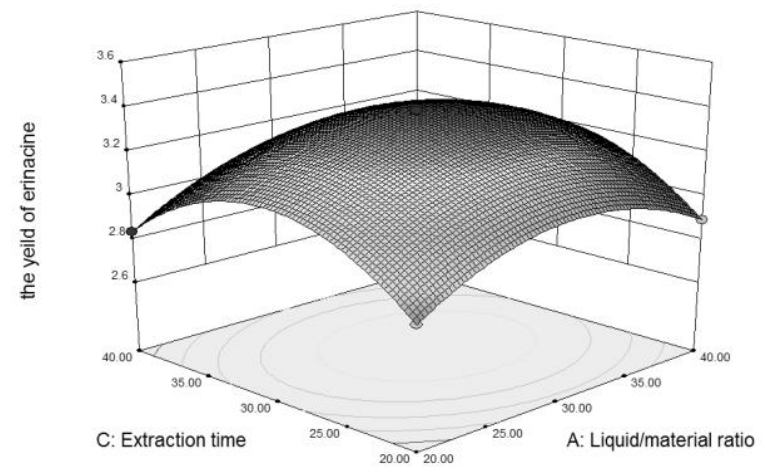

Figure 8. Response surface polts showing the effects of liquid/material ratio and extraction time on yield of the erinacine

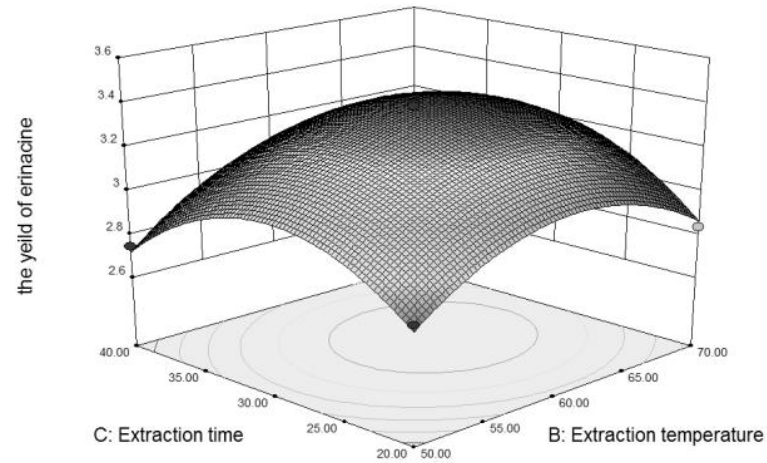

Figure 8. Response surface polts showing the effects of extraction temperature and extraction time on yield of the erinacine

\section{B. Results}

The pretreatment of enzymatic hydrolysis whose quality was one percent of the $H$. erinaceus and acid hydrolysis which was used to adjust $\mathrm{pH}$ to 2 was the key technology for improving the extraction yield of erinacine by the method of industrial alcohol reflux extraction. Significantly the extraction yield of erinacine improved from $2.4 \%$ which was extracted just by the method of industrial alcohol reflux extraction to $3.2 \%$ which was extracted by the method of industrial alcohol reflux extraction with pretreatment of enzymatic and acid hydrolysis. The influence of parameters in sequence for the yield of erinacine were extraction temperature, liquid/material ratio, extraction time. The actual extraction conditions for erinacine was liquid/material ratio $32 \mathrm{~mL} / \mathrm{g}$, extraction temperature $62^{\circ} \mathrm{C}$, extraction time $30 \mathrm{~min}$. Under the condition of the correction, the actual measured extraction yield of erinacine was $3.28 \%$. The extraction process obtained by response surface methodology was stable and reasonable, accurate and reliable. The improve of the yield of erinacine will make full use of the resources and provide a development prospect of the industrial preparation of erinacine.

\section{Acknowledgment}

This research was supported financially by the $\mathrm{N}$ ational High Technology Research and Development Prog ram of China (863 Program2014AA022205). The author $s$ are very grateful to Prof. Peilong Sun from Zhejian $\mathrm{g}$ University of Technology for assistance the usage of relevant instruments.

\section{References}

[1] Han ZH. Evaluation of in vivo antioxidant activity of Hericium erinaceus polysaccharides[J]. International Journal of Biological Macromolecules. 2013;52(1):66-71. 
[2] Kawagishi H, Mori H, Uno A, Kimura A, Chiba S. A sialic acid-binding lectin from the mushroom Hericium erinaceum[J]. Febs Letters. 1994;340(1-2):56-8.

[3] Kawagishi H, Ando M, Sakamoto H, Yoshida S, Ojima F, Ishiguro Y, et al. Hericenones C, D and E, stimulators of nerve growth factor (NGF)-synthesis, from the mushroom Hericium erinaceum[J]. Tetrahedron Letters. 1991;32(35):4561-4.

[4] Kawagishi H, Shimada A, Shirai R, Okamoto K, Ojima F, Sakamoto H, et al. Erinacines A, B and C, strong stimulators of nerve growth factor (NGF)-synthesis, from the mycelia of Hericium erinaceum[J]. Tetrahedron Letters. 1994;35(10):1569-72.

[5] Kawagishi H, Shimada A, Hosokawa S, Mori H, Sakamoto H, Ishiguro Y, et al. Erinacines E, F, and G, Stimulators of Nerve Growth Factor (NGF)-Synthesis, from the Mycelia of Hericium erinaceum[J]. Tetrahedron Letters. 1997;46(41):7399-402(4).

[6] Krzyczkowski W, Malinowska E, Suchocki P, Kleps J, Olejnik M, Herold F. Isolation and quantitative determination of ergosterol peroxide in various edible mushroom species[J]. Food Chemistry. 2009;113(1):351-5.

[7] Mizuno T, Wasa T, Ito H, Suzuki C, Ukai N. Antitumor-active Polysaccharides Isolated from the Fruiting Body of Hericium erinaceum, an Edible and Medicinal Mushroom Called yamabushitake or houtou[J]. Bioscience Biotechnology \& Biochemistry. 1992;56(2):347-8.

[8] Liu XT, Winkler AL, Schwan WR, Volk TJ, Rott M, Monte A. Antibacterial Compounds from Mushrooms II: Lanostane Triterpenoids and an Ergostane Steroid with Activity Against Bacillus cereus Isolated from Fomitopsis pinicola[J]. Planta Medica. 2009;76(5):464-6.

[9] Okamoto K, Sakai T, Shimada A, Shirai R, Sakamoto H, Yoshida $\mathrm{S}$, et al. Antimicrobial chlorinated orcinol derivatives from mycelia of Hericium erinaceum[J]. Phytochemistry. 1993;34(5):1445-6.
[10] Kim YO, Lee SW, Ch O, Rhee YH. Hericium erinaceus suppresses LPS-induced pro-inflammation gene activation in RAW264.7 macrophages[J]. Immunopharmacology \& Immunotoxicology. 2012;34(3):504-12(9).

[11] Xu Z. Isolation and identification of a new anti-inflammatory cyathane diterpenoid from the medicinal fungus Cyathus hookeri Berk[J]. Fitoterapia. 2013;86(4):159-62.

[12] Zhang AQ, Zhang JS, Tang QJ, Jia W, Yang Y, Liu YF, et al. Structural elucidation of a novel fucogalactan that contains 3-O-methyl rhamnose isolated from the fruiting bodies of the fungus, Hericium erinaceu[J]s. Carbohydrate Research. 2006;341(5):645-9.

[13] Saito T, Aoki F, Hirai H, Inagaki T, Matsunaga Y, Sakakibara T, et al. Erinacine E as a kappa opioid receptor agonist and its new analogs from a basidiomycete, Hericium ramosum[J]. Journal of Antibiotics. 1998;51(11):983-90.

[14] Shimbo M, Kawagishi H, Yokogoshi H. Erinacine A increases catecholamine and nerve growth factor content in the central nervous system of rats[J]. Nutrition Research. 2005;25(6):617-23.

[15] Lee KF, Chen JH, Teng CC, Shen CH, Hsieh MC, Lu CC, et al. Protective Effects of Hericium erinaceus Mycelium and Its Isolated Erinacine A against Ischemia-Injury-Induced Neuronal Cell Death via the Inhibition of iNOS/p38 MAPK and Nitrotyrosine $[\mathrm{J}]$. International Journal of Molecular Sciences. 2014;15(9).

[16] Zhang Z, Liu RN, Tang QJ, Zhang JS, Yang Y, Shang XD. A new diterpene from the fungal mycelia of Hericium erinaceus[J]. Phytochemistry

Letters.

2015:151-6. 